\title{
HEPATITIS B \& C; FREQUENCY OF VIRAL INFECTION IN SURGICAL PATIENTS
}

1. Senior Civil Surgeon Civil Hospital Naushahro Feroze

2. MBBS, FRCS, Dip Laparoscopic Assistant Professor of Surgery Minimal Invasive Surgical Centre, Liaquat University of Medical \& Health Sciences Jamshoro.

3. MBBS, M.S General Surgery Registrar Surgical Ward-II Liaquat University of Medical \& Health Sciences Jamshoro

4. MBBS, FCPS

Assistant Professor of National Institute of Liver \& GI Diseases (NILGID)

Dow University Hospital

OJHA Campus Karachi.

\section{Correspondence Address:}

Dr. Muhammad Paryal Tagar

Civil Hospital Naushahro Feroze

Address: Maidah Medical Centre

Naushahro Feroze.

muhammadparyaltagar@outlook.com

Article received on:

20/08/2016

Accepted for publication:

25/12/2016

Received after proof reading:

$14 / 02 / 2017$
Dr. Muhammad Paryal Tagar', Dr. Mujeeb Rehman Abbasi², Dr. Mohammad Rafique Pathan ${ }^{3}$, Dr. Hafeezullah Shaikh ${ }^{4}$

ABSTRACT... Objectives: To determine the frequency of hepatitis b \& c viral infection in surgical patients. Study Design: Descriptive case series. Place and Duration of Study: This study was conducted at surgical department of multiple hospitals and compares the results, JPMC Karachi, Civil Hospital Naushahro Feroze and Jamshoro, Pakistan from August 2014 to December 2015. Methodology: All 2645 patients were admitted for emergency and elective surgery. All patients taken detail history regarding demographic parameter and risk factors like previous surgery, blood transfusion, barbar, Road Traffic accident, haemodialysis, Tattoos/ body piercing, injecting drug user, family history of hepatitis, previous history of jaundice and Hospitalization. Hospital laboratory was used for screened HBsAg and Anti HCV using immunochromatography (ICT method). Patients excluded who were those did not need the surgery or known case of HBsAg and Anti HCV. Data collected was entered into and analyzed by using statistical package for the social science - 20. Results: Out of 2645 patients, male to female ratio were 1.9:1. The mean age was 40.2+6.12years (20 to 60 years). Out of 2645 patients, Anti HCV was positive in $288(10.88 \%)$ cases followed by HBsAg was in $152(5.74 \%)$ cases. While both positive in $36(1.36 \%)$ cases. We observed Previous surgery was main risk factor in the reactive 156(32.77\%) cases followed by Barbar, Blood transfusion were 74(15.54\%) and $47(9.87 \%)$ respectively. Conclusion: We conclude that preoperatively screening of hepatitis $\mathrm{B}$ and $\mathrm{C}$ should be performed.

Key Words: $\quad$ HBsAg, Anti HCV, Risk factors, Prevalence, Screening

Article Citation: Tagar MP, Abbasi MR, Pathan MR, Shaikh H. Hepatitis B \& C; Frequency of viral infection in surgical patients. Professional Med J 2017;24(2):278-281. DOI: $10.17957 / T P M J / 17.3592$

\section{INTRODUCTION}

In 1963 first was identified hepatitis B and hepatitis $C$ wasin1988. Both the viruses are main agents to develop the chronic liver diseases (CLD), cirrhotic condition and hepatocellular carcinoma (HCC). ${ }^{1}$ It has been reported that approximately 350 million people are infected with HBV and 170 million with HCV worldwide. ${ }^{2}$

Hepatitis B and C is a major cause of illness, death and serious public health throughout the world and in Pakistan. ${ }^{3}$ Hepatitis viral is a serious health problem that affects nearly two billion people around the world. Throughout the world the hepatitis $B$ infected are around two thousand; including $\mathbf{3 5 0}$ million have chronic liver disease. Infection with hepatitis $C$ virus appears to be local in many places in the world, with a $3 \%$ worldwide. ${ }^{4}$ More than a third of the population in the region of Southeast Asia have been infected with HBV and 80 million companies and approximately 0.2 million deaths a year. ${ }^{5}$ Pakistan faces a huge burden of these diseases. World dominate HBV and HCV community in Pakistan and $10 \%$ and $4-10 \%$ respectively. No practice to do serological detection system before surgery, which is one of the causes responsible for the increased transmission of diseases. ${ }^{6}$ Hepatitis is transmitted through contaminated blood, unsterilized injections and surgical instruments, drug abuse, dental surgery, shaving razors, sexual assault, toothbrushes and shaving by barbers. $^{7}$ The number of patients with hepatitis $B$ and $C$, received elective and emergency services has increased dramatically.

The aim of this study was to estimate the prevalence of Hepatitis B surface antigen (HBsAg) and anti$\mathrm{HCV}$ antibodies among patients undergoing 
different surgical procedures to various hospitals.

\section{MATERIALS AND METHODS}

This descriptive case series was conducted at surgical department of multiple hospitals and compares the results Civil Hospital Naushahro Feroze, Liaquat University Hospital Jamshoro and JPMC Karachi, August 2014 to December 2015. All 2645 patients were admitted for emergency and elective surgery. All patients taken detail history regarding demographic parameter and risk factors like previous surgery, blood transfusion, barbar, Road Traffic accident, haemodialysis, Tattoos/body piercing, injecting drug user, family history of hepatitis, previous history of jaundice and Hospitalization. Hospital laboratory was used for screened HBsAg and Anti HCV using immunochromatography (ICT method). Patients excluded who were those did not need the surgery or known case of $\mathrm{HBsAg}$ and Anti HCV.

\section{RESULTS}

Out of 2645 patients, 1733(65.51\%) were male

and $\quad 912(34.48 \%)$ female, male to female ratio were $1.9: 1$. The mean age was $40.2+6.12$ years (20 to 60 years). Out of 2645 patients, Anti HCV was positive in $288(10.88 \%)$ cases followed by HBsAg was in $152(5.74 \%)$ cases. While both positive in $36(1.36 \%)$ cases (Table-I). We observed Previous surgery was main risk factor in the reactive $156(32.77 \%)$ cases followed by Barbar, Blood transfusion were 74(15.54\%) and $47(9.87 \%)$ respectively (Table-II).

\begin{tabular}{|c|c|c|}
\hline Variable & No. Patients & Percentage \\
\hline \multicolumn{3}{|l|}{ Gender } \\
\hline Male & 1733 & $65.51 \%$ \\
\hline Female & 912 & $34.48 \%$ \\
\hline \multicolumn{3}{|l|}{ Age } \\
\hline 20-35 years & 623 & $23.55 \%$ \\
\hline $36-50$ years & 1123 & $42.45 \%$ \\
\hline $51-60$ years & 899 & $33.98 \%$ \\
\hline \multicolumn{3}{|c|}{ HBsAg and Anti HCV 476} \\
\hline $\mathrm{HbsAg}$ & 152 & $5.74 \%$ \\
\hline Anti HCV & 288 & $10.88 \%$ \\
\hline $\mathrm{HbsAg}+$ Anti HCV & 36 & $1.36 \%$ \\
\hline \multicolumn{3}{|c|}{ Table-I. Demographic Variable $\mathbf{N}=2645$} \\
\hline
\end{tabular}

\begin{tabular}{|l|c|c|c|c|}
\hline \multicolumn{1}{|c|}{ RISK FACTORS } & No. Patients & HBsAg & Anti HCV & HBsAg + Anti HCV \\
\hline Previous surgery & $156(32.77 \%)$ & 39 & 103 & 14 \\
\hline Blood transfusion & $47(9.87 \%)$ & 9 & 31 & 7 \\
\hline Barbar & $74(15.54 \%)$ & 17 & 55 & 2 \\
\hline Road Traffic accident & $32(6.72 \%)$ & 14 & 13 & 5 \\
\hline Haemodialysis & $11(2.31 \%)$ & 5 & 6 & 0 \\
\hline Tattoos/body piercing & $12(2.52 \%)$ & 11 & 1 & 0 \\
\hline Injecting drug user & $21(4.41 \%)$ & 6 & 15 & 0 \\
\hline Family history of hepatitis & $37(7.77 \%)$ & 16 & 18 & 3 \\
\hline Previous history of jaundice & $32(6.72 \%)$ & 15 & 17 & 0 \\
\hline Hospitalization & $54(11.34 \%)$ & 20 & 29 & 5 \\
\hline Total & 476 & 152 & 288 & 36 \\
\hline
\end{tabular}

Table-II. Risk factors for HBsAg / anti HCV in positive patients $n=476$

\section{DISCUSSION}

Viral hepatitis is common health problem around the world most third world countries including Pakistan today. ${ }^{8}$ Hepatitis B and C is spreading rapidly in much of the world. Pakistan local hepatitis $B$ and $C$, many studies were conducted in Pakistan over the past decade, and therefore the treatment and prevention strategies have been developed. Incidence in Pakistan now days approximately ranges from $4-25 \% .{ }^{9}$ Incidence of Hepatitis B \& C were found many folds higher in males as compared to females because male more involve outdoor activity lead to road traffic accident etc. In our study observed (65.51\%) were male and $912(34.48 \%)$ female, male to female ratio were 1.9:1. However in the study of Emad-Aldin Ibrahim Osman reported almost same results 1939 (61.1\%) were males and 1233 (38.9\%) were females. ${ }^{10}$ In our study observed higher incidence of viral hepatitis were in 4th and 5thdecade with mean age was $40.2+6.12$ years (20 to 60 years). While study of Abdul Majid is 
reported almost same result. ${ }^{2}$

According to WHO estimates, some 130 to 170 million are infected with HCV and more than 0.3 million died of liver disease due to hepatitis $\mathrm{C}$ each year. WHO estimated that about two million people are infected with HBV and more than 350 million have chronic hepatitis infection. $\mathrm{HBV}$ and HCV have a major infectious diseases in the world. ${ }^{11,12}$ The lack of information and health education and safe practices appear to be major risk of passing HBV and HCV in community. This is why health care units awareness mass must be made for both health care providers and the community to reduce the threat. ${ }^{11,12}$

Viral hepatitis are highly endemic in Pakistan as compared to low prevalence in Europe. ${ }^{2}$ In this study the prevalence rate $17.99 \%$, showing that HCV $10.88 \%$ is more prevalent than HBV5.74\% and combine $1.36 \%$, which is also reported in the study of Muhammad Rafique Memon which is $33(3.61 \%)$ patients were found HBsAg positive and 117 (12.8\%) were Anti-HCV positive, while 9 $(0.98 \%)$ were positive for both during preoperative workup. ${ }^{13} \mathrm{~A}$ review of literature showed that most of the infected patients had positive risk factors i.e. history of injection drug abuse, blood transfusion and chronic hepatitis. ${ }^{7,9,11}$

In our predisposing factors were observed previous surgery in 156(32.77\%) cases followed by Barbar, Blood transfusion were $74(15.54 \%)$ and $47(9.87 \%)$ respectively. However, a study of Ashraf et al reported $91.67 \%$ of patients with a history of injections, blood transfusions in $47.38 \%$ of patients, surgery in the previous $37.08 \%$ of patients, dental history and procedure of $44.29 \%$ and shaving Barber in $84 \%$ of patients. ${ }^{14}$

\section{CONCLUSION}

We conclude that preoperatively screening of hepatitis $B$ and $C$ should be performed. HCV more prevalent than HBV are common infections in our setup. Public awareness of the dangers and the most common ways of transmitting the disease to be transmitted through the print and electronic media and public awareness programs.
Copyright $@ 25$ Dec, 2016.

\section{REFERENCES}

1. El-Serag HB. Epidemiology of Viral Hepatitis and Hepatocellular Carcinoma. Gastroenterology. 2012 May; 142(6): 1264-1273.

2. Majid A, Khan MS, Shafi Ullah. Rising Prevalence of Hepatitis B and C And Risk Factors at District Headquarter Teaching Hospital Bannu, KhyberPakhtunkhwa. J Col Physicians and Surgeons Pak. 2010; 20(7):492-3.

3. Ilyas M, Iftikhar M, Rasheed U. Prevalence of hepatitis $\mathbf{B}$ and hepatitis $\mathbf{C}$ in populations of college students in Gujranwala. Biologia (Pak). 2011; 57(1\&2):89-95.

4. Ali SA, Shah FA, Ahmed K. Prevalence of hepatitis b and $\mathbf{c}$ virus in surgical patients. Pak J Surg. 2007; 23(2):109-112.

5. Marcellin P. Hepatitis B and hepatitis $\mathbf{C}$ in 2009. Liver Int 2009; 29:1-8.

6. Sarwar MZ, Shah SFH, Farooq A, Ahmad QA, Khan SA. Pre-operative screening for hepatitis $b$ \& $\mathbf{c}$ in general surgical population and their risk factors. Annals 2014; 20(2):182-7.

7. Surahio AR, Talpur AA, Kella NL, Memon AS. Prevalence of hepatitis $\mathbf{b} \& \mathbf{c}$ in patients for emergency surgery: an institutional experience. Med Channel. 2012; 18(1):84 - 86 .

8. Nelson PK, Mathers BM, Cowie B, et al. Global epidemiology of hepatitis $B$ and hepatitis $C$ in people who inject drugs: results of systematic reviews. Lancet $2011 ; 378: 571-83$.

9. Shaikh AA, Memon SR, Paryani JP, Shaikh U, Bhatti AJ. Prevalence of Hepatitis $\mathbf{B}$ and $\mathbf{C}$ in Urological Patients. Gomal J Med Sciene 2012; 10(1):107-110.

10. Osman El, Abdulrahman NA, Abbass O, Omer WH, Saad HA, Hamid MMA. Prevalence of Hepatitis B surface antigen and Hepatitis $C$ virus antibodies among pre-surgery screened patients in Khartoum, Central Sudan. J General \& Molecular Virol. 2012; $4(1): 6-9$.

11. Umar M, Bushra H, Ahmad M, Khurram M, Usman S, Arif $M$, et al. Hepatitis $\mathbf{C}$ in Pakistan: A Review of Available Data. Hepat Mon 2010; 10(3):205-214.

12. Baldo V, Baldovin T, Trivello R, Floreani A. Epidemiology of HCV infection. Curr Pharm Des. 2008; 14:16461654.

13. Memon MR, Shaikh AA, Soomro AA, Arshad S, Shah QA. 
Frequency of hepatitis $b$ and $c$ in patients undergoing elective surgery. J Ayub Med Coll Abbottabad 2010; 22(2):167-170.
14. Chaudary MA, Rizvi F, Afzal M, Ashraf MZ, Niazi S, Beg $A$, et al. Frequency of risk factors for hepatitis $B$ (HBV) and Hepatitis C Virus (HCV). Ann Pak Int Med Sci 2010; 161-3.

\title{
PREVIOUS RELATED STUDY
}

ljaz-ul-Haque Taseer, Liaq Hussain, Sohail Safdar, Ahsanullah M. Mirbahar, Muhammad Aftab Akbar. HEPATITIS B, HEPATITIS C \& HIV; KNOWLEDGE AMONG GENERAL PUBLIC OF PERIPHERAL AREAS OF MULTAN. (Original) Prof Med Jour 16(3) 370-376 Jul, Aug, Sep, 2009.

Muhammad Zaheer Haider, Naseem Ahmad, Muhammad Yasrab, Aamir Mehmood Malik, Mamoona Javed. SCREENING FOR HEPATITIS B\&C: A PREREQUISITE FOR ALL INVASIVE PROCEDURES (Education) Prof Med Jour 13(3) 460-463 Jul, Aug, Sep, 2006.

Riaz Ahmed Bhutta, Nauman Ahmad, M. Jawad Popalzai, Mujtaba Ali, Sajid Mir, Adnan Ajmal, Asad Ahmed, Arslan Arshad, Muhammad Mohsin Ghafur. PREVALENCE OF HEPATITIS B \& HEPATITIS C (Original) Prof Med Jour 10(1) 66 - 69 Jan, Feb, Mar, 2003.

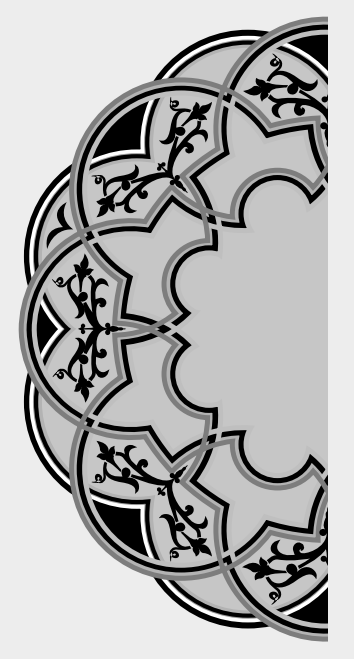

\section{"We know what we are, but know not what we may be."}

\author{
William Shakespeare
}

\section{AUTHORSHIP AND CONTRIBUTION DECLARATION}

\begin{tabular}{|c|l|}
\hline Sr. \# & \multicolumn{1}{|c|}{ Author-s Full Name } \\
\hline 1 & Dr. M. Paryal Tagar \\
2 & Dr. Mujeeb Rehman Abbasi \\
3 & Dr. M. Rafique Pathan \\
4 & Dr. Hafeezullah Shaikh \\
\hline
\end{tabular}

\section{Contribution to the paper}

Conception and design, Statistical expertise, Critical revision of the article for important intellectual content Data Collection Drafting of the article Statistical expertise 